\title{
Corpos do poder: operadores jurídicos na periferia de São Paulo
}

JACQUELINE SINHORETTO

\section{Apresentação}

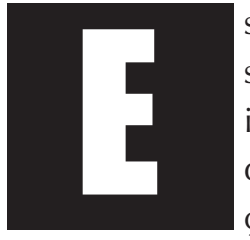

ste texto se propõe a ensaiar algumas interpretações de situações observadas durante uma pesquisa de campo no interior de um equipamento público que reúne serviços de acesso à justiça e à cidadania. No decorrer da observação de campo, várias situações que envolviam a interação dos usuários do serviço com as autoridades públicas (juízes, promotores e delegados) instigaram-me a aprofundar a investigação das relações políticas.

Tendo como referencial de análise a interpretação de Michel Foucault sobre o poder, o tema da corporificação e o lugar dos corpos no modelo de interpretação tornou-se central. Assim, a análise das relações políticas nas situações sociais ${ }^{1}$ observadas não pode deixar ao largo a interpretação sobre a produção cultural dos corpos e o modo como eles interagem no espaço político. Além disso, a abordagem aqui proposta busca responder algumas inquietações surgidas na observação, cujo sentido era para mim nebuloso.

\footnotetext{
* Doutoranda em Sociologia / USP com Bolsa de doutorado concedida pela CAPES.

1 A metodologia de análise das situações sociais foi introduzida na antropologia por Max Gluckman (1987). Trata-se de um método de registro e interpretação etnográficos, que difere da etnografia clássica por buscar evidenciar as correlações de força que produzem as cerimônias, os rituais e as interações cotidianas dos mais diferentes segmentos que compõem a realidade social que está sendo observada. Esta metodologia busca historicizar essas correlações de força, a fim de compreender como elas se tornaram possíveis.
} 


\section{A pesquisa}

Trata-se de um levantamento de dados sobre a implementação e o funcionamento dos Centros de Integração da Cidadania - CIC, programa da Secretaria de Justiça e Defesa da Cidadania do Estado de São Paulo, que visa melhorar o acesso à justiça e a segurança das populações residentes em bairros periféricos, distantes de outros equipamentos públicos, onde se verifique também pouca incidência de ações não-governamentais e onde haja altas taxas de violência combinadas com precariedade nas condições de vida.

É uma experiência intersecretarial e interinstitucional que procura articular os serviços de justiça, segurança pública, documentação, assistência social, assistência ao trabalho, moradia e outras parcerias que possam surgir localmente.

O programa nasceu de um projeto de aproximar as instituições e os profissionais de segurança e justiça, da população da periferia de São Paulo, e foi inicialmente idealizado por um grupo de penalistas engajados com a defesa da democratização do sistema de justiça criminal.

Há quatro unidades em funcionamento na cidade de São Paulo. Outras duas unidades já foram inauguradas em municípios da região metropolitana, havendo previsão de construção de novas unidades. Também o Governo Federal tem um programa de financiamento de unidades em outras regiões do país, com diversas unidades já instaladas e outras em fase de implementação, contribuindo ainda para o fomento do programa estadual em São Paulo.

Um primeiro levantamento empírico ocorreu entre fevereiro e junho de 2002, com visitas diárias às quatro unidades de São Paulo, em que foram observadas audiências, salas de espera, atendimentos, realizadas entrevistas com funcionários e operadores alocados no programa, bem como com usuários. Os idealizadores do projeto também foram entrevistados. ${ }^{2}$ Posteriormente, as informações foram complementadas por obser- 
vações realizadas nos anos de 2003 e 2004, no âmbito da pesquisa de doutorado.

\section{A periferia}

Por se tratar de um programa voltado à população dos bairros de periferia, carentes de serviços de justiça e de segurança, tudo no Centro de Integração da Cidadania parece carregar esta marca. As instalações foram cuidadosamente pensadas para não exibirem a suntuosidade que marca os prédios públicos nas áreas centrais da cidade. Os primeiros funcionários públicos e os operadores jurídicos a servirem no CIC passaram por um treinamento que visava, além do preparo para o trabalho em parceria, orientá-los para o atendimento à população da periferia, qualificada sempre como carente e ignorante dos direitos e da organização do Estado.

Os próprios idealizadores do projeto, um grupo composto por desembargadores de justiça, juízes de alçada, promotores de justiça e delegados de altas classes, realizaram uma visita a um bairro da Zona Leste de São Paulo, Cidade Kemel, onde puderam constatar, com surpresa, as condições de vida dessa população. Nessa ocasião, reuniram-se com moradores e ouviram as reclamações e reivindicações quanto ao acesso à justiça e quanto à segurança das pessoas e das residências. Saíram de lá impressionados com o fato de que os cidadãos comuns daquela localidade não eram capazes de reconhecer as funções públicas desempenhadas pelos visitantes. "Eles não sabiam a diferença entre um juiz e um promotor!" - horrorizam-se ainda hoje, depois de 10 anos, os homens da justiça.

\footnotetext{
3 Trecho da entrevista com o desembargador de justiça 1, sobre a visita à Cidade Kemel: "Então, começamos a fazer perguntas para saber o que é que eles conheciam do Judiciário. E aí então foi uma surpresa geral. Eles não tinham a mínima noção de autoridade e de agente de autoridade, eles não sabiam o que era um juiz. Nem imaginavam. Promotor então! Os colegas perguntavam o que era promotor público. Nem imaginava do que se tratava. Delegado de polícia eles tinham uma idéia longe. E o símbolo da autoridade para eles era a Policia Militar que aparecia lá de vez em quando para atender alguma coisa. Este é o símbolo da autoridade para eles. Eles não sabiam nada!"
} 
A proposta inicial dos Centros de Integração da Cidadania era, portanto, de levar os órgãos do Estado a sediar-se nos bairros, a fim de aproximar a população dos agentes da autoridade pública, a fim de que, através do uso cotidiano do equipamento para a resolução de problemas do dia-a-dia, a população começasse a tomar contato com o funcionamento da justiça e começasse a conhecer e reconhecer os direitos de cidadania. ${ }^{4}$

Embora pudessem, talvez, até intuir que o desconhecimento das leis, das instituições e dos direitos pudesse estender-se para além, a preocupação dos proponentes da ação governamental era com a periferia. De uma parte, porque compartilhavam de alguma forma com as idéias do campo político de esquerda que concebe que toda ação governamental deve atender prioritariamente aos mais pobres e menos favorecidos por outras políticas; de outra parte, porque compartilhavam da representação da periferia como carência, como espaço prioritário onde se origina a violência e o crime, onde surgem os criminosos, onde as violações se multiplicam - lugar, portanto da desordem. Ambos compartilhamentos não são, de modo algum, excludentes.

A representação da periferia das grandes cidades como locus do crime é corrente no senso comum da cultura brasileira. A periferia é a fronteira física, mas se associa fortemente com a idéia de fronteira moral da sociedade. Esta representação pode ser compreendida com a análise de Mary Douglas (1976) sobre a idéia de perigo que ronda qualquer fronteira. Segundo a antropóloga, a necessidade humana de conferir unidade às experiências desordenadas faz com que os sistemas de pensamento estejam sempre operando a partir de categorias em que a oposição entre os

\footnotetext{
4 Trecho de entrevista com o desembargador de justiça 2, sobre o CIC: "Como tudo no social, não é ele a solução. Mas no dia em que nós...que nós tivéssemos ele assim em tudo quanto é lugar... Porque o dia em que o povo começasse a saber dos seus direitos... Na idade mental que a gente tem, e vocês têm a mesma idade mental minha, embora eu infelizmente tenha quatro vezes a idade de vocês, a gente sabe que isso tudo vai depender dessa ascese que houver... o povo entendendo, reclamando... o dia em que o sujeito chegar na sala do juiz e sentar na cadeira e 'o sr. levanta daí', 'não, doutor, eu não tô sentado na sua cadeira, isso aqui é do povo' ...né, vai demorar, mas nós temos que um dia chegar nisso, nesse conceito de cidadania... E as pessoas saberem que não são objetos, que não são coisas, não é?"
} 
pares de classificação é radical e exagerada. "É somente exagerando a diferença entre dentro e fora, acima e abaixo, fêmea e macho, com e contra, que um semblante de ordem é criado". (Douglas, 1976, p. 15).

Assim, ao se trabalhar com categorias binárias opostas e muito bem delimitadas, a situação da liminaridade e da fronteira entre dois mundos é problemática, fonte de medos, perigos e tabus.

A periferia como a fronteira do social, ${ }^{5}$ é concebida como o espaço em que as pessoas são mais ligadas à natureza, submetidas às regras da sobrevivência, muito distantes dos bens simbólicos mais importantes, distantes da lei, distantes do Estado. Na periferia, as casas não são adequadas, a educação das crianças não é adequada, as famílias são "desestruturadas", as mulheres têm muitos filhos, de pais diferentes. Mais recentemente, um novo mito sobre a liminaridade social da periferia se tem fortalecido: a periferia é o domínio do tráfico de drogas, território dos traficantes, onde só se pode entrar ou sair com o seu consentimento. Um tal lugar é, evidentemente, ameaçador à ordem. É, na visão douglasiana, fonte de perigo e poluição.

O trabalho de Teresa Caldeira nos ajuda a compreender como este processo de estigmatização, de classificação se vai construindo numa associação entre pobreza e crime. "O crime e os criminosos são associados aos espaços que supostamente Ihes dão origem, isto é, as favelas e os cortiços, vistos como principais espaços do crime". (Caldeira, 2000, p. 79). Nesta pesquisa, o espaço do crime é a periferia.

\footnotetext{
5 Transcrição de trecho de entrevista o desembargador de justiça 1, sobre a visita à Cidade Kemel: "Nossa Senhora! Depois da Zona Leste, você passa o campo do Corinthians e vai embora e ainda anda mais duas horas e meia de carro. Uma loucura! Até parece que está saindo do Brasil! Longe, longe, longe. Estou tentando... mas me foi muito fotográfico: nós chegamos, a impressão que eu tive é que estava em um faroeste norte-americano. Terra, não tinha nenhuma rua calçada, terra, ruas de terra. Aquelas casas muito simples. E até brincava, dizia: olha aí que vocês vão encontrar negócio para amarrar cavalo. Tinha impressão que estava fora de São Paulo. Eaí, nos levaram para o único lugar assim mais, mais, mais...não, não, não digo apresentável, mais em uma construção pouco melhor que era um ginásio do Estado. Aí, nós fomos para o ginásio e estava assim de gente Igesticula enfático], tinha toda a gente que você pode imaginar, tinha muita gente. Era mulher, jovens, adolescente, criança, velho, mãe com criança no colo, mulher grávida e homens de todos os tipos da periferia".
} 
Sendo deste modo, a periferia (assim no amorfismo e na indeterminação da palavra) é o lugar onde a reestruturação da ordem, o controle da criminalidade, a redução da violência, deve começar. Numa vertente política mais conservadora, controlar a periferia é manter a ordem em toda a sociedade. Em outra vertente, mais à esquerda, trata-se de expandir a fronteira política, incorporando espaços e pessoas da periferia através de "políticas de inclusão". Agradando a uns ou a outros, as propostas de políticas públicas voltadas para a periferia sempre vão girar em torno da idéia de administrar as fronteiras.

\section{Um projeto político}

Os Centros de Integração da Cidadania foram idealizados com o objetivo de produzir transformações na administração da justiça. Não pode esta ser uma tarefa fácil. O sistema de administração da justiça numa sociedade não existe de forma autônoma, parecendo muito difícil atingir o resultado esperado quando se concebe este sistema como parte da organização social. Muitas e muitas páginas já foram escritas buscando explicar como os sistemas de administração da justiça nas sociedades contemporâneas (inclusive no Brasil) são parte de mecanismos muito maiores de classificação e hierarquização dos segmentos sociais e de manutenção e legitimação de certa organização social. Como no objetivo deste ensaio não cabe uma reflexão mais aprofundada sobre a questão, por ora bastará mencionar que tanto no senso comum como na literatura específica encontram-se muitas referências sobre estreitas afinidades estratégicas entre a organização da administração da justiça e as dimensões econômica, social, simbólica e espacial da organização social. ${ }^{6}$ Dito em outras palavras, para mudar a Justiça é necessário mudar a própria sociedade, assim como para mudar a sociedade é necessário transformar a Justiça.

6 A este respeito existem pesquisadores que são referência, dos quais indicarei apenas alguns trabalhos: Adorno, 1994; Corrêa, 1983; Lima, 1995. 
No caso dos idealizadores do projeto estudado, a meta de mudar a sociedade através da inovação na administração dos conflitos pela Justiça era clara. Acreditava-se que a democratização da sociedade brasileira e a introdução do respeito incondicional aos direitos humanos só poderiam ocorrer na medida em que a justiça assumisse outras funções e feições. Ao invés de agentes da repressão penal na periferia, a partir dos $\mathrm{CIC}$, os operadores da justiça passariam ao papel de agentes da efetivação da cidadania na periferia.

O exercício e a gestão do poder no funcionamento dos $\mathrm{CIC}$, especificamente na relação entre os operadores da justiça e cidadãos comuns é o problema central deste ensaio.

\section{O poder - considerações metodológicas}

Michel Foucault representa uma inflexão nos estudos políticos quando propõe o abandono do modelo da soberania, no qual o poder emana de um centro político e se enfraquece nas extremidades, em favor da adoção de uma analítica do poder que o supõe onipresente em toda parte, exercendo-se de modo capilar.

Seu enfoque está em como o poder se exerce, buscando desprender o pensamento do leitor da idéia de que o poder é alguma coisa intrínseca do sujeito, que alguém pode deter, transferir. Seu combate intelectual é contra o conceito de soberania que havia norteado a construção das teorias políticas de maior sucesso até então. $\mathrm{O}$ autor busca demonstrar como a construção da teoria da soberania tem como figura central o rei, sendo a tarefa da teoria ser instrumento ou justificação de seu poder, e a tarefa dos juristas a de fixar a legitimidade do poder soberano. Para Foucault, falar em legitimidade do poder ou em direitos legítimos da soberania é uma forma de mascarar o fato da dominação, é uma tentativa de olhar para o consenso, quando a natureza das relações políticas é a luta (Foucault,2002).

A fim de dissecar as relações de dominação e apropriação política sob 
um novo olhar, não mais centrado no rei, mas disperso pelo corpo social, não mais pautado pelo paradigma da obediência, mas preocupado em compreender a sujeição, cinco são as precauções fundamentais para o desenho da pesquisa, enunciadas por Foucault, num dos cursos que ofereceu no Collège de France - transcrito no livro Em Defesa da Sociedade:

Primeira: deslocamento do olhar para a periferia, para as extremidades do corpo social, para as instituições locais, para além da lei e da regulamentação, observando as técnicas de intervenção do poder na produção dos efeitos que busca.

Segunda: observar o exercício do poder em sua face externa, isto é, observando seus efeitos e não interrogando as motivações internas dos agentes - o que seria supor a existência de um centro do poder e supor que o poder pode ser detido por alguém. O deslocamento do olhar para a extremidade e para os súditos implica que o principal para a análise política é entender como se produzem os súditos, que procedimentos de sujeição podem ser observados e como eles operam, "a partir da multiplicidade dos corpos, das forças, das energias, das matérias, dos desejos, dos pensamentos, etc.", produzindo efeitos materiais sobre os corpos (Foucault, 2002: 33).

Terceira: o poder é algo que circula, que funciona, que se exerce. Não pode ser detido, partilhado, transferido, aplicado, represado, não pertence a indivíduo, grupo ou classe. A dominação não deve ser entendida de forma homogênea, mas como particularidade do exercício, da apropriação conjuntural de força. E como só existe em circulação, só existe em redes, pelas quais circulam os indivíduos que sucessivamente submetem e são submetidos na concretude das relações.

Quarta: embora circule e forme redes, a distribuição do poder nunca é igualitária nem está localizada em ponto nenhum. O que ocorre são apropriações, investiduras, colonizações, deslocamentos, transformações, rupturas, continuidades, que não estão localizadas num sujeito ou num 
grupo ou classe. Os agentes do poder, aqueles que operam seus instrumentos, que aplicam as técnicas são as mais insuspeitas pessoas concretas. Para entender os mecanismos do poder não adianta interrogar os grandes sujeitos históricos como burguesia, classe, pois novamente seria supor que o poder tem um centro. É preciso demonstrar que certos arranjos produzem utilidades políticas e lucros econômicos que podem ser apropriados e colonizados em mecanismos que se solidificam.

Quinta: à noção de ideologia se contrapõe a noção de produção, acumulação e circulação de dispositivos de saber que se operam a partir de técnicas de observação, registro e investigação e que se constituem em verdades.

Trata-se de um referencial metodológico que está centrado na observação da constituição dos corpos, do seu controle, das suas interações e dos efeitos concretos que essas interações produzem.

\section{O corpo como um problema teórico}

Uma maneira de interrogar como funciona o poder na sociedade contemporânea é interrogar-se sobre como foram constituídos os corpos, como ganharam esse contornos, que discursos regulam a sua apresentação e o cuidado com eles, já que consistem em um dos mais visíveis e verificáveis efeitos de poder. De acordo com Thomas Csordas, Michel Foucault ofereceu uma importante contribuição, ao lado de Pierre Bourdieu e Maurice Merleau-Ponty, para a emergência do corpo como um problema teórico (Csordas, 2000). A partir dessa emergência, não se pode mais considerar o corpo como um fato da natureza, mas deve-se entendê-lo como resultado de um processo histórico e dinâmico de corporificação, como um efeito de poder.

Judith Butler propôs uma associação entre as visões douglasiana e foucaultiana sobre o corpo, apresentando-o como sendo constituído de 
fronteiras variáveis, cuja superfície e permeabilidade é politicamente regulada. Para Mary Douglas, como já foi mencionado, os tabus sobre as fronteiras do corpo correspondem aos tabus sobre as fronteiras do social, sendo os mecanismos de definição do que constitui o "eu" e o que é exterior estruturalmente correlacionados aos mecanismos que definem "nós" e os "outros" na ordem social. Controlar os corpos é controlar aquilo que é perigoso para a ordem social, aquilo que são suas descontinuidades e fronteiras, uma vez que o corpo é moldado por ou é expressão da força social, um microcosmo da sociedade. As fronteiras do corpo se contraem e se expandem conforme as pressões sociais (Butler, 1997; Douglas, 1976). Já de acordo com Foucault, a anátomo-política do corpo humano e sua docilização para o trabalho, bem como as regulações da população são os dois pólos constitutivos do poder sobre a vida, regime de poder característico das sociedades capitalistas desde o século XVIII. O regime do biopoder tornou-se um elemento indispensável ao desenvolvimento do capitalismo, na medida em que garantiu uma inserção controlada dos corpos no aparelho de produção, por meio de um ajustamento dos fenômenos de população aos processos econômicos. Mas, mais do que isso, a anátomo-política do corpo permitiu majorar as forças, aptidões e a vida em geral dos trabalhadores, sem por isso torná-los mais difíceis de sujeitar (Foucault, 1991). O corpo é o lugar onde as técnicas de bio e anátomo-política se encontram, daí dizerse que Foucault concebe o corpo como sendo atravessado e constituído pelo poder. Este poder não tem apenas efeitos negativos, de interdição, mas sobretudo efeitos positivos, criadores de sujeitos, efeitos de classificação, hierarquização e regulação, normalização. Nos termos deste regime de poder, a saúde do corpo é a saúde do corpo social.

Ao desnaturalizar a constituição do corpo humano, Foucault fala mesmo em um corpo da burguesia, um corpo de classe, dotado de uma sexualidade própria, cercado pelos cuidados de saúde, higiene, que têm a finalidade de produzir uma descendência e fortalecer uma raça; sendo 
autoconstituído para marcar sua diferença de classe em relação aos outros: o corpo vigoroso, saudável, com determinado uso dos prazeres e objeto de discursos de verdade e de poder, tratando-se, quando da sua emergência, de uma auto-afirmação da burguesia. A classe "que se tornava hegemônica no século XVIII se atribui um corpo para ser cuidado, protegido, cultivado, preservado de todos os perigos e de todos os contatos, isolado dos outros para que mantivesse seu valor diferencial" (Foucault, 1988, p. 116). Diferencial em relação ao valor do corpo da nobreza, que se distinguia pelo seu sangue, e diferencial em relação às classes trabalhadoras, que terão seus corpos constituídos e normalizados a partir das práticas discursivas próprias da burguesia, tornando-se úteis e dóceis para o trabalho. Sua hegemonia se mantém pelo controle e vigilância dos corpos, pela gestão das populações através da saúde pública, das políticas habitacionais, do controle demográfico, pelas necessidades de formação de uma mão-de-obra especializada e valiosa. Mas esta tecnologia de controle que caracteriza a hegemonia da burguesia se mantém não apenas pela gestão da vida, da sua própria e dos outros, mas pela escolha de quem deixar morrer. As guerras, inerentes ao processo de constituição dos Estados-nações, só foram possíveis em função dos discursos racistas que separam os corpos politicamente úteis para viver daqueles politicamente úteis para morrer (Foucault, 2002).

Partindo dessa análise foucaultiana, Butler desenvolveu o conceito de que o corpo é performative, isto é, sua superfície é um efeito de discursos regulativos que criam identidades normalizadas para os corpos: o corpo feminino, o corpo masculino, o corpo saudável, o corpo reprodutivo, o corpo homossexual. A idéia de performance (chamada a partir de agora de desempenho) é a idéia da fabricação de uma identidade corporal (ao mesmo tempo subjetiva e objetiva), que é imitada infinitamente tendo como referência um mito de originalidade. Assim, todo corpo constituído como corpo feminino desempenha sua feminilidade imitando um mito de feminilidade, que é a própria norma, constituída e reforçada pelos discur- 
sos de saber-poder. A identidade corporal desempenhada é constituída por "um conjunto de práticas imitativas que se refere lateralmente a outras imitações e que, ademais, constrói a ilusão de um eu sexuado interior e primário ou parodia o mecanismo dessa construção"7 (Butler, 1997). Assim, a imitação é o desempenho individual da norma, e a paródia é aquele desempenho que torna evidente a existência de uma norma que está sendo deliberadamente (mal) imitada. Por evidenciar a normalização das condutas é que Butler deposita nas paródias um potencial de resistência, de inflexão e até de ruptura. É o caso das drag queens que, ao parodiar a corporalidade feminina exagerando nas características distintivas, abre possibilidades para a crítica dos padrões normativos que definem o que é feminino e o que é masculino, apontando até mesmo para a possibilidade de superação do binarismo de gênero através de uma síntese: um corpo que pode conter ao mesmo tempo o masculino e o feminino.

\section{O encontro dos corpos na periferia}

Do mesmo modo como existe uma corporalidade de classe, uma corporalidade de gênero, os operadores da justiça designados a atuar na periferia, no âmbito dos Centros de Integração da Cidadania, possuem uma corporalidade. Sua identidade de classe social é tão marcada que chega a ser comum defini-la através da imagem do gueto. Além da classe, existe uma identidade racial (branca e sulista) entre os operadores, em tensão com os tipos mestiços e nordestinos freqüentes entre a população que atendem ${ }^{8}$ (Guimarães, 2002). Esta corporalidade é também atraves-

\footnotetext{
7 A tradução do inglês foi livremente feita para a utilização neste texto, optando-se por traduzir gendered como sexuado, na tentativa de tornar o mais inteligível possível, neste contexto, o trecho transcrito.

8 Guimarães (2002) reflete sobre o preconceito contra baianos e nordestinos em São Paulo como uma das manifestações da problemática racial. Os membros de uma organização de advogados negros - Instituto do Negro Padre Batista - relataram as dificuldades do acesso da população negra à justiça em razão da invisibidade da diversidade e do conflito racial no aparato judicial.
} 
sada pela hierarquia de gêneros, como se verá.

Existe uma apresentação corporal de juiz, ou de advogado, que é destacadamente homogênea em relação às outras. Para além do fenômeno da uniformidade na aparência física, existe uma identidade lingüística que os marca e diferencia. A linguagem jurídica é um mundo à parte. Na tradição do Direito continental europeu, à qual nosso Direito é filiado, há uma grande preocupação formal, conferindo aos termos e categorias sentidos muito precisos, que expressam status jurídicos particulares. Seja na ritualizada prática de sua atividade, seja na descontração do dia-a-dia, com os colegas de ofício, a linguagem dos operadores da justiça é peculiar.

A vestimenta é um símbolo de distinção de grande relevância para este grupo. Tanto é verdade que, até há poucos anos, era proibido por regulamento que as mulheres entrassem nos edifícios da Justiça trajando calças compridas. ${ }^{9}$ Mas, mais do que o uso de saias, são os taillieurs e as saias retas, no comprimento dos joelhos, que diferenciam juízas, promotoras e advogadas de outros estratos profissionais de elite. São sutis diferenças na escolha de modelos, de acessórios, de tecidos, de comprimentos, decotes, recortes, estampas, que são suficientes para diferenciar os operadores da justiça dos profissionais do mercado financeiro, por exemplo. No estrato aqui estudado, tudo é cuidadosamente sóbrio. As ousadias são muito pouco toleradas e apenas quando marcam, de fato, uma posição privilegiada no interior do próprio estrato. Um respeitado desembargador, por exemplo, pode ostentar uma armação de óculos menos tradicional, fazendo sempre a importante ressalva: "é italiana". Ou, no outro extremo, um desembargador aposentado, referência intelectual e política de um certo grupo, pode adotar velhos ternos, com décadas de uso e surradas

9 Ainda atualmente, após a promulgação da Constituição Federal e de leis complementares que expressamente proíbem a discriminação de qualquer natureza no acesso aos edifícios públicos e privados (vide os avisos que figuram em todos os elevadores da cidade de São Paulo), os porteiros dos edifícios dos fóruns ainda barram pessoas na entrada sob justificativas de trajes inadequados, conforme relato de um informante, de 23 de abril de 2003, que presenciou o impedimento da entrada de uma mulher no Fórum de Santo Amaro. 
gravatas com estampas antigas. Soa como uma "opção pela pobreza", algo como uma simplicidade franciscana. Entretanto as posições intermediárias e baixas exigem um rígido guarda-roupa.

Uma situação que comprova a rigidez da etiqueta de vestimenta e o seu significado político como definidor de fronteiras do grupo foi coletada por ocasião dos exames do concurso para ingresso no Ministério Público paulista em 2003. Duas estudantes do quarto ano de Direito - já acostumadas aos rituais e à corporalidade do estrato jurídico próprias do ambiente e do entorno do Largo São Francisco ${ }^{10}$ - iam assistir aos exames orais públicos quando cruzaram com a pesquisadora e espontaneamente revelaram o receio de não conseguir entrar no edifício que sedia o Ministério Público por causa da vestimenta. Havia circulado um boato nos corredores da Faculdade de que uma mulher havia sido barrada sob a justificativa de que eram exigidos "trajes forenses". As duas informantes discutiram calorosamente, sem a interferência da pesquisadora, sobre quais seriam os critérios definidores dos "trajes forenses" e chegaram à seguinte conclusão: trata-se de um tipo específico de calçado (scarpin ou chanel), meiacalça, um certo comprimento de saia (na altura do joelho ou logo abaixo) e um corte determinado de roupa. A discussão das duas jovens testemunha a existência de uma política da vestimenta que determina as fronteiras simbólicas de inclusão/exclusão do universo jurídico.

Entre os operadores, há ainda diferenças. A rigidez é mais acentuada entre os membros da magistratura. No Ministério Público, a rigidez é menos pronunciada, e entre os advogados é onde se encontra a maior diversidade, até porque o número de profissionais é muito maior, permitindo uma relativa diversidade social, sendo, na representação simbólica das carreiras, a menos associada ao poder. Há que se considerar ainda que os

\footnotetext{
10 Onde se localiza a mais tradicional Faculdade de Direito, cujos mecanismos de distinção fazem com que seja conhecida como "São Francisco" - ou "San Fran" para os iniciados - ao invés de "Direito da USP", como se identificam os outros cursos da Universidade de São Paulo, ou mesmo outros cursos de Direito em outras instituições de ensino.
} 
advogados, embora consistam numa corporação poderosa, organizada em torno da Ordem dos Advogados do Brasil - instituição influente tanto na política interna dos órgãos da Justiça quanto na política nacional - não estão vinculados a uma única instituição. Por outro lado, os grandes escritórios de advocacia, organizados no modelo da moderna empresa capitalista são, ao que tudo indica, cuidadosos vigilantes das fronteiras desta corporalidade. ${ }^{11}$

Há também segmentações no interior desta elite, que traduzem disputas, lutas, resistências, deslocamentos, defasagens de poder: os operadores que procuram fugir da ostentação material reforçam ainda mais um certo "figurino" que tende ao sóbrio, visando a mensagem do desprendimento material: qualquer terno, portanto azul ou cinza; qualquer camisa, portanto branca; qualquer sapato, portanto preto; qualquer gravata, portanto no tom do terno ou vermelha, sempre lisa, de pequenas estampas ou listada. A versão feminina geralmente comporta mais variações, acompanhando o padrão de gênero na sociedade abrangente, mas dificilmente escapa-se da saia reta, do casaquinho e do sapato fechado de salto médio e bico fino, predominantemente em tons pastéis.

Trata-se de uma normalização dos corpos que se manifesta num gosto de classe ${ }^{12}$ sofisticado e caro. Evidentemente muito diferente daquele que se encontra junto à população usuária da Justiça em geral, e do CIC, em particular. Isto constitui um objeto de preocupação para os idealizadores e gestores do programa CIC que talvez suspeitem da importância da norma na produção de efeitos de poder. Os próprios operadores também revelam preocupação com sua apresentação corporal. Nas unidades do CIC pude constatar, em alguns operadores, um esforço em apresentar-se de maneira menos rígida. Como por exemplo, realizar audiência e atendi-

11 Nos grandes escritórios paulistanos, é evidente a subordinação de gênero, bem como a subordinação etária. Também é evidente a supremacia branca. Os controles da fronteira de classe chegam a assumir requintes, como no relato de um caso envolvendo uma jovem advogada, funcionária de um escritório médio, que recebeu orientações reiteradas de não deixar os clientes saberem que não possuía carro. Para não macular a imagem do escritório, a advogada deveria sempre escusar-se com um episódio de oficina ou com o dia de rodízio, para desfazer a "gafe" de ser vista utilizando o transporte público.

12 A expressão gosto de classe é de Bourdieu, 1983. 
mentos sem paletó, coisa que nos demais postos de trabalho só é tolerada no intenso verão e em condições muito especiais. Nas mulheres, maior freqüência de calças compridas, roupas mais folgadas e sapatos baixos. Não obstante, manter-se a distinção em relação a outros servidores públicos do próprio CIC e em relação, sobretudo, aos usuários. Todavia excessos de ostentação são severamente criticados por outros membros, como se vê na reprodução abaixo de um trecho de entrevista sobre o CIC.

Entrevista com desembargador de justiça 3 (D3) e três entrevistadoras:

"D3 - É fazer do CIC - era a idéia nossa - um momento na carreira do juiz. Entende? O CIC seria forçosamente um local por onde qualquer juiz na sua carreira teria de passar!

E1 - Então teria que haver trezentos CICs...

D3 - Mas é evidente! Não digo trezentos CICs, mas pelo menos um número bem maior de CICs e haver uma boa vontade do Tribunal na designação de juiz e fazer o juiz cumprir isso daí, que era o mais difícil.

E2 - Uma escola, né?

D3 - E por quê? Por quê? Porque nós saímos, nós juizes, saímos de um estrato social que não é aquele estrato social. E continuamos a desconhecer. Ficamos cada vez mais ilhados aqui dentro do nosso próprio estrato, com o tipo de relacionamento que são aquelas pessoas do dia-a-dia nosso, que não têm nada a ver com aquilo, não é verdade? E...é...é...eu converso com advogado que tem o mesmo padrão social meu, com o promotor que tem o mesmo padrão, com...enfim, com pessoas que estão vivendo o mesmo nível de vida, eu não tô lá! O juiz, se começasse a fazer sua carreira por lá, eu tenho certeza que ele modificaria a sua forma de entender o social. E isso era um dos propósitos! [batendo levemente na mesa] Tava incluído nessa idéia do CIC a idéia de que fosse um 
estágio para a carreira de juiz!

E2 - Obrigatório?

D3 - Obrigatório. Em que momento, eu não sei. Se seria bem no início, se seria quando chegasse a São Paulo.

[...]

D3 - O que forçaria a ter um promotor público, o que forçaria a ter um delegado de polícia, e aí os outros órgãos viriam...um defensor público...e os outros órgãos viriam quase que por inércia, eles teriam chegado aí porque não teria outro jeito. Né? Mas...

E1 - Então, mas aí talvez precisasse disso aí, de uma reforma legal mesmo na própria estrutura dos tribunais de justiça...

D3 - Não, não é uma coisa impossível de ser feita! Como eles podem designar, eles podem criar também. Eles precisavam estar convencidos disso! Acontece que isso é uma estrutura simples, fechadíssima! Agora...né? Uma idéia desta ordem é uma idéia que é considerada chocante! O que que vai fazer um juiz num bairro pobre? Nós tivemos certa ocasião uma promotora pública, você se lembra dela? Vestida...

E3 - Saltinho fino!

D3 - Na última estica!

E2 - Cabelo!

D3 - Cabelo...quer dizer, o que que ela tinha que ver com aquele CIC? Nada!

E3 - Ai, era até engraçado...

D3 - E todos nós, de uma certa forma, temos a mesma procedência, ou nós abrimos os nossos olhos e começamos a ver com olhos de...que há uma outra realidade, ou então nós vamos continuar fechados na nossa torre de babel! Na nossa torre de ouro, de babel não tem nada! E vivemos nos nossos guetos, satifeitíssimos..."

Para além de uma apresentação corporal, existe uma postura corporal própria dos homens (e mulheres) da Justiça. Presenciou-se, no decorrer 
da pesquisa, um juiz de um Tribunal de Alçada recusar uma entrevista ao programa dominical Fantástico da TV Globo, em que a produção pedia ao entrevistado para comentar alguns dados estatísticos sobre o sistema de justiça criminal. A questão que motivou a recusa não era o assunto, tampouco o receio de adotar uma posição política definida, já que o entrevistado era presidente de uma associação civil e já assinara editoriais sustentando suas posições político-ideológicas. A recusa foi motivada pelo cenário da entrevista: uma caminhada por uma rua no centro de São Paulo. O juiz explicou, em conversa informal, que poderia vir a ser motivo de chacota entre os colegas de cargo, pois a situação poderia ser interpretada como pouco digna a um homem de sua posição. Seria mais adequado uma gravação no gabinete, assim como o programa soava demasiado popular.

Seja onde for, uma sala de audiência do Poder Judiciário contém sempre os mesmos elementos e obedece à mesma disposição espacial, assegurando o desempenho desta postura. Chama-se a atenção para o fato de que o ritual da audiência, a vestimenta do juiz e as instalações físicas das salas, tudo isso é regulamentado pelo Código de Processo, pelos procedimentos costumeiros do Processo e por provimentos dos Tribunais de Justiça. Assim, não se trata de uma questão de escolha pessoal do magistrado apresentar-se desta ou daquela forma às audiências ou dirigir-se às partes em tais ou quais maneiras. Trata-se, em primeiro lugar, da existência de uma norma jurídica que regula as condutas; em segundo, de procedimentos burocráticos tidos como necessários para assegurar a imparcialidade do juiz e a racionalidade dos feitos. Não obstante, ao analista há de interessar a observação desta circunscrição e a produção do distanciamento político do magistrado, que denuncia seu significado exatamente na medida em que se torna objeto de normatização, e também de normalização. À critica de não haver sentido em problematizar um comportamento que é, na verdade, a adesão a uma regra, responde o 
analista que a adesão às regras é um campo privilegiado de reflexão nas ciências sociais, já que nem todos aderem da mesma forma, com a mesma intensidade a todas as regras, como é um exemplo o uso das togas em audiência. Durante todo o período de observação de campo, esteve em vigência um provimento do Tribunal de Justiça de São Paulo que torna obrigatório o uso de toga pelo magistrado nas audiências, entretanto, a adesão a esta regra - verifica-se na prática - é inequivocamente seletiva, resultando em cuidadosa análise de sua conveniência por cada magistrado, nas diferentes situações com que se depara no exercício profissional.

Numa audiência cível, como é o caso das que se verificam nos $\mathrm{CIC}$, defronte à parede oposta à da porta situa-se um tablado sobre o qual fica a mesa do juiz. À esquerda, o chefe de audiência (que não raro é uma mulher), atrás do computador. Compondo a forma de um $\mathrm{T}$ com a mesa do juiz, fica a mesa em que se sentam as partes, ou seja os litigantes e seus advogados (se houver): cada qual de um lado. Ninguém olha o juiz de frente, assim como, por causa do tablado, ninguém pode contemplá-lo na altura dos olhos. Quem dá um depoimento senta-se à frente do escrevente, mas não o olha, pois seu diálogo é com o juiz, que dita ao escrevente o conteúdo do depoimento. Assim, não se trata propriamente de um diálogo, mas de uma inquirição seguida de tradução e versão.

Conforme o caso, o tipo do processo e a conveniência, o juiz pode decidir se um depoimento é dado na presença dos demais ou reservadamente, ausentando-se os outros da sala. No caso de depoimento reservado, a parte contrária não tem como tomar ciência do que foi dito durante o rito. Só poderá efetuar a leitura dos autos mais tarde, quando lhe forem concedidas vistas. Mesmo estando presentes, os demais participantes estão proibidos de manifestar-se oral ou gestualmente, durante os depoimentos, podendo manifestar-se apenas através de perguntas dirigidas ao juiz e por ele traduzidas e versadas ao depoente. Isto faz com que o rito seja desempenhado única e exclusivamente para o juiz, o único que de- 
tém todos os fragmentos da cena.

Numa audiência de instrução e julgamento - o tipo mais comum observado no $\mathrm{ClC}$ - ao final dos depoimentos (instrução), o juiz pausadamente dita sua sentença (julgamento) para o escrevente. É ouvindo o que o juiz dita, que, na condição de espectadores passivos, as partes ficam sabendo qual é a decisão. Neste momento, torna-se evidente a todos que o ritual da justiça não é desempenhado para as partes, mas para o juiz. A permanência das partes na sala enquanto o juiz dita sua decisão é quase uma atitude indiscreta, é como acompanhar uma reflexão em voz alta. É a publicização da sua interioridade, da sua consciência, do seu pensamento. É o ato do poder, já que esta reflexão decide o futuro das partes. Finda a prolação da sentença, cala-se o juiz e as partes continuam em silêncio, sem poder expressar contentamento ou desagrado, enquanto ouvem o escrevente explicar-lhes, em voz baixa - como quem não quer incomodar as reflexões do juiz - o que foi decidido. Ou, então, o escrevente, sempre em voz baixa convida os presentes a aguardarem lá fora para lerem e assinarem a ata. Cada um lê em silêncio o conteúdo da sentença, assina e se retira.

Toda a situação é calculadamente construída em torno do corpo do juiz, da sua invulnerabilidade, do seu direito à palavra e ao controle da palavra do outro. Os presentes não têm controle do seu próprio corpo, dos gestos e muito menos das palavras. A palavra da parte lhe é expropriada, concedida no momento certo, caçada nos demais. Só é lícito responder ao que for perguntado, sob pena de falso testemunho ou desacato, podendo resultar numa condenação à prisão. Cada depoente é alertado sobre o frágil limite entre o exercício de sua fala e o cometimento de um crime. Expropriada também, uma vez ser o seu registro intermediado pelo juiz, que amputa, interpreta, transmuta. Mais liberdade tem o advogado ou o promotor que, expressando-se nos limites do discurso formal jurídico, tem direito a compor seu próprio texto, ainda assim regulado pela 
linguagem jurídica.

A circunscrição do corpo do juiz pelo ritual estende-se por todos os seus atos no ambiente forense. No fato de existirem elevadores, corredores e sanitários privativos de juizes, outros privativos de advogados e aqueles permitidos ao homem comum. No fato de haver uma ordem para o embarque e o desembarque dos elevadores e nas passagens das portas. Há duas regras: mulheres e idosos na frente e mais importantes na frente, seguindo as senhoras. Ocorre que é de bom tom ceder a vez, e uma espécie de duelo simbólico pode travar-se nestas situações em que ganha aquele que não ceder à fraqueza de passar primeiro. Blagues à parte, o embaraço que geralmente se instala nas portas e nos elevadores demonstra o grau de hierarquização e de vulnerabilidade dos corpos. Juizes vão na frente, mas cedem sua passagem às mulheres e aos idosos, de corpos mais vulneráveis. Quando há dois juizes da mesma posição, quem passa por último reafirma sua invulnerabilidade.

Tal é a codificação da alocação dos corpos no espaço e o desempenho das posições de poder no deslocamento físico que alguém acostumado a este ambiente estranha os demais espaços, como se vê na narrativa abaixo, em relação aos espaços universitários.

Transcrição de trecho de entrevista com desembargador de justiça 2: "Há um pouco de pose, porque a função... porque quando se é juiz, a gente logo se transforma em gênio, né? O cartório fala: 'oh, mas aqui nunca passou um juiz como vossa excelência'. 'Ah, que bom'. 'Aquela sentença de vossa excelência é um brilho'. Nas sentenças nossas há sempre uma parte vencida e uma vitoriosa. A vencida, que ataca nossas decisões - eu falo nós porque eu me sinto ainda muito juiz, embora aposentado há 20 anos, eu admiro muito a função, alguns pensam que não, mas eu admiro sim - então o advogado que sucumbiu, que perdeu a demanda, ele sabe que vai encontrar o juiz de novo, ele começa sempre 
dizendo 'não obstante o brilho excepcional do magistrado, por ora...' Tem uns termos assim... 'Ora essa sentença de sua excelência não se ouve com aquele brilho que o caracteriza, tal...'. Já o outro já fala só do nosso brilho, né, que a sentença vem sempre confirmar...[risos]

E como eu lecionava muito, isso me ajudou um pouco na vida, porque a descontração dos alunos, os alunos entrando no elevador antes da gente, a gente vai acostumando com aquilo, né. Agora isso na Justiça já vê assim com um... o sujeito não está no seu lugar e etc. A estas alturas, são invencíveis! Eu mesmo devo ter sido um juiz muito posudo, devo ter sido autoritário também, a gente não sabe, não é? Eu mesmo... [...]

Nós apostávamos... é aquilo do Vinícius, o operário faz a coisa e a coisa faz o operário... Os juizes que foram [para o $\mathrm{ClC}$ ], a notícia que a gente tem é que eles tão empolgados. Juizes, promotores, procuradores... O procurador é outra peste... A peste não é só juiz não... Gente de pose é juiz, algum é promotor, algum é procurador. Isso é uma doença! E ela é contagiosa, não há meio d'ocê... não há remédio. Mas diz que o pessoal que foi pro $\mathrm{CIC}$, todos eles começam a... Isso nós temos que acreditar..."

Um outro entrevistado, gestor de uma unidade do CIC a ser instalada numa parceria entre Governo Federal e Município revelou que uma das preocupações no desenho das instalações da unidade era a exigência de sanitários privativos para magistrados, promotores de Justiça, delegados e oficiais da Polícia Militar. Cuidados de separação dos corpos que, se não observados, poderiam tornar-se objeto de resistência ao programa. Se o perigo é concreto ou simbólico, importa aos objetivos desta análise comprovar a observância destes cuidados de separação, circunscrição e 
hierarquização.

A percepção de que a democratização das instituições e da administração da justiça passa pelo desempenho de uma outra postura dos operadores da justiça já estava presente entre os idealizadores do CIC. A aposta deles era na possibilidade de produzir avanços concretos, a partir da interação cotidiana entre os operadores e a população demandante. De fato, a alocação dos corpos no CIC parece, em algumas circunstâncias, não obedecer à mesma lógica. Os espaços são simples, não há elevadores e a sala do juiz é, de certo modo, tão vulnerável quanto qualquer outra. Contudo, ao observar a interação política entre as autoridades judiciais e os jurisdicionados durante a ocorrência das audiências e analisar toda a construção corporal de circunscrição, diferenciação e hierarquização do ritual judicial, torna-se difícil acreditar que seja possível transformar a administração da justiça sem transformar os ritos, as regras de condução de um processo judicial, estruturado para a extração da verdade e livre convicção do juiz. O próprio saber jurídico como conhecimento exclusivo e hermético dos bacharéis de Direito é parte do desempenho da norma, e precisaria ser interrogado quanto à sua utilidade política. A desigualdade entre os corpos ritualmente circunscritos dos operadores e corpos nãocircunscritos dos cidadãos comuns não parece compatível com a construção de uma cidadania pautada na igualdade jurídica e na democracia, para tentar um diálogo com Teresa Caldeira (2000). Ainda que se consiga o resultado esperado de legitimação da justiça para a resolução de conflitos, o sistema persistirá validando um exercício de poder, que assegura a prevalência de uma classe sobre as outras, de uns bairros sobre os outros, de um modo de vida sobre os outros. Tratar-se-ia, nessa hipótese, de um importante componente da estratégia biopolítica: reduz-se a violência física sobre os corpos da periferia, garantindo seu assujeitamento aos aparelhos do Estado.

Entretanto espera-se que o desempenho dos juizes que vão à perife- 
ria indique possibilidades políticas de resistência, introduza rupturas na constante diferenciação entre os corpos, que caracteriza a atividade judicial clássica. Mas, como já foi dito, as possibilidades de transformação são sempre historicamente limitadas. A possibilidade da ruptura passa - com inspiração em Judith Butler (1997) - pelo desempenho consciente de um estilo de ser juiz que, repetido inúmeras vezes, será capaz de operar uma reelaboração, no plano mítico, da identidade dos juizes, que será capaz de introduzir ruídos, distorções, reinterpretações da norma. Este processo não pode ser levado a cabo individualmente por um juiz bem intencionado, já que o próprio ritual da Justiça expropria o juiz de seu discurso autônomo, de sua corporalidade e até mesmo de sua identidade original de classe. A linguagem jurídica expropria o sujeito de sua fala livre e lhe confere uma fala regulada, regulamentada, atravessada por uma correlação de forças que ela valida. O ritual da audiência expropria o juiz de sua autonomia de entendimento em favor de um exercício de poder (expresso na sentença inúmeras vezes repetida "responda só o que for perguntado"). O saber jurídico é a alma que aprisiona o corpo do magistrado num regime de poder que perpetua uma determinada hierarquização. A ruptura com este regime de poder pode estar condicionada à ruptura com a corporalidade do magistrado, libertando os corpos para o exercício de sua autonomia de comunicação e entendimento. Essa autonomia poderia devolver aos homens e mulheres do Direito o papel de ad vocare, isto é, ser "chamado para ajudar".

O exercício da crítica do presente deve aprofundar-se e se dirigir aos elementos mais sutis de assujeitamento, sob pena de se descartarem as possibilidades de ruptura e de inflexão, envolvendo toda uma intenção transformadora nas malhas do mesmo regime de poder - ou nas palavras de um entrevistado, remendando uma roupa que continuará a ser mesma. 


\section{Referências}

ADORNO, Sérgio. Crime, justiça penal e desigualdade jurídica: as mortes que se contam no tribunal do júri. Revista USP, n. 21, p. 132-151, mar./maio. 1994.

BOURDIEU, Pierre. Gostos de classe e estilos de vida. In: ORTIZ, Renato (org.). Pierre Bourdieu. São Paulo: Ática, 1983 (Col. Grandes Cientistas Sociais).

BUTLER, Judith. Excerpts from Gender Trouble. In: MEYERS, D. T. (org.). Feminist social thought: a reader. Londres, Routldge, 1997, p.112-128.

CALDEIRA, Teresa P. R. Cidade de muros. Crime, segregação e violência em São Paulo. São Paulo: Edusp, 2000.

CORRÊA, Mariza. Morte em família. Representações jurídicas de papéis sexuais. Rio de Janeiro: Graal, 1983.

CSORDAS, Thomas. The Body's Career in Anthropology. In: MOORE, Henrietta L. (ed.). Anthropological theory today. Cambridge: Polity Press, 2000.

DOUGLAS, Mary. Pureza e perigo. São Paulo: Perspectiva, 1976.

FOUCAULT, Michel. Em defesa da sociedade. São Paulo: Martins Fontes, 2002.

. História da sexualidade I. A vontade de saber. 10 $\underline{\underline{a}}$ ed. Rio de Janeiro: Graal, 1988.

. Vigiar e punir. História da violência nas prisões. 9ª ed. Petrópolis: Vozes, 1991.

GLUCKMAN, Max. Análise de uma situação social na Zululândia Moderna. In: FELDMAN-BIANCO, Bela (org.). Antropologia das sociedades contemporâneas: métodos. São Paulo: Global, 1987, parte I, p. 227-267.

GUIMARÃES, Antonio S. A. Classes, raças e democracia. São Paulo: FUSP/Ed. 34, 2002.

HADDAD, Eneida G. M.; SINHORETTO, Jacqueline; PIETROCOLLA, Luci G. Justiça e segurança na periferia de São Paulo: os centros de integração da cidadania. São Paulo: IBCCRIM, 2003. 
LIMA, Roberto Kant de. A polícia na cidade do Rio de Janeiro: seus dilemas e paradoxos. Rio de Janeiro: Forense, 1995.

Recebido: 13/09/2004

Revisado: 10/11/2004

Aceite final: 16/11/2004

\section{Resumo}

O texto propõe-se a interpretar situações observadas em pesquisa de campo realizada em um equipamento público inovador quanto à organização dos serviços de justiça e segurança. Trata-se de levantamento de dados sobre a implementação e o funcionamento dos Centros de Integração da Cidadania CIC, programa governamental desenvolvido em São Paulo (Brasil), que visa meIhorar o acesso à justiça e à cidadania e também à segurança das populações residentes em bairros periféricos. O programa apoiava-se na visão de que a democratização da sociedade brasileira relaciona-se intimamente com a adoção, pelos órgãos da Justiça, de outras funções e feições: ao invés de agentes da repressão penal na periferia, os operadores da justiça, a partir dos $\mathrm{CIC}$, passariam ao papel de agentes da efetivação da cidadania nos espaços de maior exclusão social. Para a análise, elegeu-se o referencial analítico foucaultiano, em que é central o tema da corporificação - a produção cultural e política dos corpos. Interroga-se em que medida o desempenho dos operadores no programa indica possibilidades políticas de resistência, introduz rupturas na constante diferenciação entre os corpos, que caracteriza a atividade judicial clássica, abre possibilidades para a emergência de uma nova corporificação dos agentes públicos da justiça, reduzindo a desigualdade entre operadores e cidadãos comuns (de modo a contribuir para a construção de uma cidadania pautada na igualdade jurídica e na democracia). Procura-se desvendar os sutis mecanismos pelos quais a atuação do Estado cria efeitos de validação do poder de uma classe sobre as outras.

Palavras-chave: acesso à justiça, operadores da justiça, corporificação, poder, desigualdade. 


\section{Power bodies: legal operators in São Paulo's outskirts}

\section{Jacqueline Sinhoretto}

This text aims at interpreting situations observed in field research carried out on an innovative public facility regarding organization of justice and security services. It is a survey about implementation and workings of Integrated Citizenship Centers, known as CIC - a government program developed in São Paulo (Brazil) in order to improve access to justice and citizenship rights as well as the safety of populations of neighborhoods located in the outskirts. The program was based on the view that democratization of Brazilian society is closely related to the adoption of different functions and features by Judiciary organs: instead of being agents of criminal repression in the outskirts, justice operators, based on the CICs would become agents of citizenship rights in spaces of more social exclusion. For the analysis, Foucaultian thought was elected as the analytical reference, to which the issue of corporification - the cultural and political production of bodies - is crucial. The question posed is to which degree the performance of the program's operators points out possibility of resistance, introduces ruptures in the permanent differentiation between bodies, which mark classical legal activity, opens possibilities for the emergence of a new corporification of justice's public agents, thus reducing inequality between operators and common citizens (so as to contribute to the construction of a citizenship based on legal equality and democracy). We try to reveal the subtle mechanisms through which State action creates effects of power validation of one class over others.

Key words: Access to justice, Justice operators, Corporification, Power, Inequality. 